\title{
BAJO EL SOL DE CUBA: INFLUENCIAS DE LA REVOLUCIÓN CUBANA EN LOS ORIGENES DE LA NUEVA IZQUIERDA REVOLUCIONARIA CHILENA (1959-1964)
}

\author{
Marco Antonio Álvarez Vergara ${ }^{1}$
}

\section{Resumen/ Abstract}

Más de seis décadas han transitado desde el triunfo de la Revolución Cubana y, hasta la fecha, no ha existido un estudio que indague la real influencia sobre las izquierdas en Chile. El presente artículo de investigación procura desentrañar tal magnitud en los orígenes de la nueva izquierda revolucionaria chilena (1959 - 1964), esclareciendo las vinculaciones políticas, teóricas y discursivas de esta con el proceso caribeño. Este cometido, lo abordaremos a través de la trayectoria político - orgánica de tres de los principales referentes del proceso de confluencia insurreccional: Clotario Blest, Enrique Sepúlveda y Miguel Enríquez.

Palabras claves: Revolución Cubana, nueva izquierda revolucionaria chilena, lucha armada, revolución socialista.

\section{UNDER THE SUN OF CUBA. INFLUENCES OF THE CUBAN REVOLUTION IN THE ORIGINS OF THE NEW CHILEAN REVOLUTIONARY LEFT (1959 - 1964)}

More than six decades have passed since the triumph of the Cuban Revolution and, to date, there has been no study that investigates its real influence on the Chilean left. The objective of this article is to unravel the influence of this historic milestone in the emergence of the new Chilean revolutionary left (19591964), identifying its political, theoretical and discursive links with the Caribbean process. This task will be addressed through the analysis of the political-organizational trajectory of Clotario Blest, Enrique Sepúlveda and Miguel Enriquez, three of the main referents of the insurrectional confluence process.

Keywords: Cuban Revolution, new Chilean revolutionary left, armed struggle, socialist revolution

\footnotetext{
${ }^{1}$ Fundación Miguel Enríquez. E-mail: marcoantonioalvarezvergara@gmail.com
} 


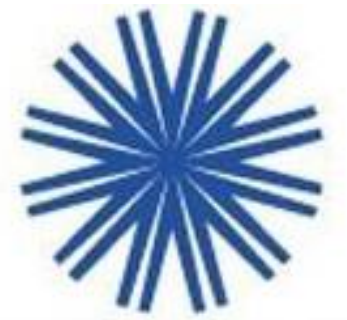

\section{Introducción}

Emir Sader, destacado sociólogo brasileño, afirma que la Revolución Cubana tuvo más influencia en América Latina que el desarrollo de la Revolución Bolchevique en Europa (2006: 26). De ser cierta esta premisa comparativa, obliga a interrogarnos sobre cuáles fueron los reales alcances de la revolución encabezada por Fidel Castro en el territorio de Chile. El presente artículo de investigación se centrará en el influjo que tuvo la insurrección caribeña en su primer lustro (1959-1964) sobre la "nueva izquierda revolucionaria chilena" (NIRCH).

Las representaciones hegemónicas existentes sobre la relación de la NIRCH con la Revolución Cubana han sido comprendidas en forma de metáfora "espacial", es decir, como si la construcción de la alternativa revolucionaria en Chile hubiese sido proyectada como un satélite y, mantenida en órbita, por los controles de mando de Fidel Castro y sus hombres. A contrario sensu, existe la tesis que relativiza tal influencia, postulando una evaluación natural de la izquierda radical chilena desde la década de 1920 hasta su "despertar" insurreccional en los años 60 (Palieraki 2014). Ambas conjeturas, una caricaturesca, la otra de enfoque de progreso lineal, no han permitido develar la real magnitud de las vinculaciones políticas, teóricas y discursivas que son materia de nuestro estudio.

Como todo novedoso proceso de construcción política, el origen de la NIRCH tuvo un carácter difuso y contradictorio, agudizado por lo diversidad política y generacional de los actores participes de la confluencia. En tal crisol: trotskistas, estalinistas, maoístas, anarcosindicalistas, excomunistas, ex socialistas, jóvenes guevaristas, etcétera; constituyeron un proceso de reagrupamiento revolucionario, cuestionador de los partidos de la izquierda tradicional, anclando como arquetipo las enseñanzas de la Revolución Cubana (Álvarez 2014).

Para abordar la influencia de la Revolución Cubana en la NIRCH, evocaremos la trayectoria de quienes consideramos fueron sus referentes más emblemáticos en la temporalidad trazada: Clotario Blest, Enrique Sepúlveda y Miguel Enríquez. Representando disimiles tradiciones políticas, cada uno de estos tres militantes serán estudiados en virtud de su carga generacional, trayectoria organizacional y devenir político-ideológico. Blest, el más longevo, sin militancia partidaria orgánica anterior, hasta 1960 realizó 
su despliegue político meramente en el campo de la acción sindical. Sepúlveda, en su antípoda, cargaba con más de tres décadas de militancia política en las filas de la izquierda disidentes a los Partidos reformistas de masas. Por último, Enríquez por una cuestión etaria sincronizó su voluntad revolucionaria con la del proceso caribeño.

\section{Revolución Cubana y nueva izquierda latinoamericana}

El triunfo de la Revolución Cubana descerrajó indiscutidamente una nueva etapa histórica para los pueblos de "Nuestra América", desencadenando un flujo y reflujo de lucha armada en el continente entre fuerzas revolucionarias y contrarrevolucionarias con disímil intensidad en tiempo y espacio (Regalado 2012: 140). Su originalidad no sólo recayó en una mera autonomía metodológica para la conquista del poder político, sino que al recrearse "bajo el liderazgo ajeno al modelo ideológico del comunismo estalinista” (Löwy 2007: 46), es decir, de la hegemonía soviética imperante por décadas, aportó en la configuración de un innovador marxismo latinoamericano. Aparejado a ello, surgieron estructuras revolucionarias de nuevo tipo con vocación insurreccional. Vania Bambirra las definirá:

Son las organizaciones que se formaron en función de una oposición teórica a la línea política de los PC. Planteaban como objetivo inicial fundamental constituirse en vanguardia contra el reformismo, para posteriormente crear un partido revolucionario que se presentase como alternativa real frente a los partidos reformistas, y agudizar la lucha de clases, preparando las condiciones para la insurrección popular (...) Concebian el carácter de la revolución como socialista (con algunas variaciones si habría o no gobierno de transición) y la vez antiimperialista y anticapitalista, conducida por la alianza obrero -campesina, bajo el liderazgo de la clase obrera. En general, estas organizaciones se compusieron mayoritariamente de jóvenes estudiantes independientes, algunos pocos trotskistas y ex militantes de los PC y de los partidos populistas (en aquellos casos en que se logró una superación más profunda de estos). (1972:58).

Esta nueva izquierda latinoamericana ha contado con distintas periodizaciones desde un ángulo temporal, como la de Claudio Pérez y Pablo Pozzi, que en su trabajo conjunto identifican una primera fase de desarrollo entre 1959 y 1969 la que denominaron «periodo del foco», caracterizada por una medular influencia guevarista (Pozi y Pérez 2012: 129). Sin embargo, siguiendo con Bambirra, nos quedamos con su definición de un "primer momento" de despliegue político-orgánico de este fenómeno revolucionario, el que transitará hasta el año de 1964, destacándose en este ciclo insurreccional: las nuevas formaciones políticas en Brasil, la instalación del movimiento guerrillero en Guatemala, la formación del Frente de 
Liberación Nacional de Nicaragua, las experiencias de lucha armada en Venezuela, las acciones revolucionarias en Colombia, etcétera. (Bambirra, 1972: 58).

Por la proximidad geográfica, la NIRCH generó un particular interés por las diversas experiencias guerrilleras surgidas en el Perú: el Frente de Izquierda Revolucionaria (FIR), de un alto componente campesino, siendo liderado por el trotskista Hugo Blanco en el sur de ese país; en fractura con la izquierda tradicional peruana nació el Movimiento de Izquierda Revolucionario (MIR), encabezado por Luis de la Puente; y, el Ejército de Liberación Nacional (ELN), nucleado mayoritariamente de jóvenes, los que eran comandados por Héctor Béjar (Letts 1981).

La Revolución Cubana, no solo operó como ejemplo inspirador para las nuevas organizaciones revolucionarias latinoamericanas. Desde sus albores, consagró una estratégica internacionalista de solidaridad para con ellos. Estableció una doble diplomacia: la formal, protocolar, dedicada a mantener las relaciones de Estado. Y la informal, "semi-clandestina", destinada a vincularse con los partidos de las izquierdas y los movimientos insurreccionales del mundo. Esta última, se institucionalizó en 1961, con la creación de la Dirección General de Liberación (DGL), dependiente del recién creado Ministerio del Interior. En su calidad de viceministro, este organismo de inteligencia exterior fue constituido y liderado por Manuel Piñeiro, conocido como el comandante Barbarroja, quien informaba y respondía directamente a las órdenes de Fidel Castro. (Juan Carretero, entrevista personal, febrero y septiembre 2017).

Todos los nuevos movimientos revolucionarios del continente buscaron la venía de este organismo, que en definitiva constituía el apoyo de la Revolución Cubana a sus proyectos localistas. Juan Carretero, de nombre político Ariel, fue el oficial de la inteligencia cubana encargado de la DGL para América Latina. Cada país latinoamericano, dependiendo del desarrollo de sus luchas, tenía un agente encargado de las relaciones en general, o uno para cada organización específica. El primer lustro de las décadas de 1960, la inteligencia cubana priorizó dos líneas de vinculación en Latinoamérica: la primera, que dice relación con los pasos de preparación de la guerrilla del Che Guevara en el Cono Sur, específicamente en Bolivia y Argentina; y la segunda, orientada a los países que mantenían flujo de lucha armada, como eran los casos de Venezuela, Perú, etcétera. (Juan Carretero, entrevista personal, febrero y septiembre 2017). 
La nueva izquierda latinoamericana situó en las categorías políticas de vanguardia obrero-campesina, el impulso de la revolución socialista y conquista del poder por la vía insurreccional. Sin embargo, sus esfuerzos, en muchos casos, se limitaron a sobrevivir ante las puntas de lanzas contrainsurgentes en el continente. Estas nóveles organizaciones, terminaron siendo aniquiladas por las fuerzas del orden en América Latina. A modo de evaluación de esta primera experiencia, Bambirra acusa "dos pecados capitales" de la izquierda ante el descenso de estos movimientos insurreccionales en el lustro 1959-1964: uno, la "inmadurez político-ideológica" de las recién creadas estructuras político-militares. El otro, el rol que tuvieron los partidos reformistas de masas, que intentaban contener a toda costa los causes de lucha armada provenientes del Caribe (Bambirra 1972: 45). Como todo "primer momento", en este claroscuro continental se fue delineando la resonancia chilena de la nueva izquierda latinoamericana.

\section{Clotario Blest: líder del reagrupamiento revolucionario chileno}

Clotario Blest Riffo, comenzó su proceso de politización en torno a las charlas que dictaba Luis Emilio Recabarren en los albores de la década de 1920. En los años 30, como trabajador del servicio público, se incorporó activamente a la lucha sindicalista. En 1943 creó la Asociación Nacional de Funcionarios Públicos (ANEF), asumiendo como presidente. El mismo cargo ostentará una década después, al fundar la Central Unitaria de Trabajadores (CUT), principal organización de la clase obrera chilena (Barría 1971). Sin militancia partidista, dedicó las primeras décadas de su vida a la acción sindical con énfasis en la unidad de la clase trabajadora chilena. (Orellana 2012).

La victoria de la Revolución Cubana trajo aparejada de inmediato una dantesca campaña internacional de difamación mediática en su contra. Los dardos de la prensa conservadora del mundo alardearon sobre la creación de los tribunales revolucionarios, los que comenzaron a dictar sentencias de fusilamientos contra los responsables de crímenes de guerra en la época de Fulgencio Batista. Para contrarrestar la desinformación, Fidel Castro, convocó al ejercicio de lo que denominó "Operación Verdad". Bajo ese mandato, emisarios del nuevo gobierno revolucionario viajaron por diferentes países del mundo narrando detalles del proceso cubano. A Chile, la segunda semana de marzo de 1959 llegó una delegación encabezada por Violeta Casal, emblemática combatiente guerrillera en la Sierra Maestra, reconocida por haber sido la voz de "Radio Rebelde". 
Gracias a ello, Clotario Blest tuvo la oportunidad de empaparse a través de una de sus protagonistas de los alcances de la reciente victoriosa Revolución Cubana. Aprovechando la estadía de la delegación visitante, la tarde del 13 de marzo de 1960 la CUT, la Federación de Estudiantes de la Universidad de Chile (FECH) y el círculo de periodistas, organizaron un homenaje en la Plaza Artesanos. Uno de sus principales oradores fue Blest, quien dijo:

En nombre de los trabajadores chilenos, obreros, empelados y campesinos, doy el saludo más cordial a este puñado de revolucionarios cubanos que pusieron fin a una de las tiranías más oprobiosas de América. Este pequeño grupo de héroes de las montañas es un ejemplo para América Latina, donde las tiranías económicas siguen siendo el flagelo de sus pueblos. Ellos supieron derrotar un régimen sangriento, sostenido por el oro norteamericano, y demostraron que se puede vencer a los tiranos, por fuertes que estos sean, cuando se está guiado por ideales de libertad y justicia, como está impregnada la revolución liberadora de Cuba.

Junto con ser reelegido presidente de la CUT en el II Congreso Nacional efectuado en diciembre de 1959, se estampó en el evento congresal "un apoyo incondicional a la Revolución Cubana" (Barría 1971: 97). A su accionar sindical, Clotario Blest acoplará un protagónico despliegue en Chile de solidaridad con la Revolución Cubana. Encabezó mítines, redactó proclamas, llegando a constituir y encabezar junto a importantes actores políticos de la izquierda el "Comité Chileno de Solidaridad con Cuba". El influjo del proceso caribeño en Clotario hasta mediados de 1960 se redujo a exacerbar su internacionalismo y antiimperialismo, cualidades que anclaba con anticipación al triunfo de los barbudos comandados por Fidel Castro.

Esa activa solidaridad con Cuba llevó al presidente de la CUT a ser uno de los invitados de honor por el régimen revolucionario al Primer Congreso Latinoamericano de la Juventud, a realizarse en la ciudad de La Habana. El día inaugural, un 28 de junio de 1960, las palabras de cierre estuvieron a cargo del comandante Ernesto Che Guevara, quien al iniciar su discurso hizo un distingo para saludar "al representante del pueblo de Chile, Clotario Blest, cuya voz juvenil ustedes escucharon hace un momento, y cuya madurez, sin embargo, puede servir de ejemplo [...]."

Admiración mutua surgió del encuentro entre Clotario Blest y Ernesto Guevara. "Le acompañé a varias charlas que les dio a los campesinos", dirá Clotario, "mantuvimos largas conversaciones. Me di cuenta 
que era un hombre cautivante que a todos nos impregnaba de sus ideales y de espíritu de lucha" (Echeverría 2013). Además, en sus días en Cuba le tocó vivir un momento importante de la historia de la Revolución Cubana: la nacionalización de las empresas norteamericanas. Luis Vitale, compañero de Blest en la CUT, añade: "allí en plena Sierra Maestra, junto a los guajiros, se ha convencido plenamente de la necesidad de la Revolución" (1961: 9). Óscar Ortiz, su secretario personal durante años, sobre los efectos de su viaje a la isla caribeña, dice que un nuevo optimismo reposará sobre Blest (2008: 252).

A su regreso a Chile, Clotario Blest no volverá a ser el mismo, arengando en un acto público que "la Sierra Maestra se ha trasladado a todo el macizo andino". Además, cuestionó la falsa democracia, proponiendo "permanecer con el arma al brazo y formar las milicias del pueblo para defender a la Revolución Cubana y a nuestra propia revolución, cuya llegada es inevitable..." (26 de agosto de 1960). De estas palabras, se desprende un giro en la discursividad política de Blest, donde las ideas de "acción directa de masas" y de la "Revolución Chilena" comienza a destacarse en su repertorio político. En consecuencia, transitará por el "momento más radicalizado y revolucionario de su extensa trayectoria sindical" (Orellana: 656).

En su espacio natural, la acción sindical, incorpora de inmediato los preceptos de la radicalidad política. Clotario Blest logró convencer al resto de la directiva de la CUT de realizar un mitin de protesta contra las alzas del gobierno de Alessandri el día 3 de noviembre de 1960 en la Plaza Artesanos. Luego de convocar a una huelga general para el día 7 de noviembre, los más de 30 mil trabajadores lo escucharon llamar a "levantarse en armas y derribar a este gobierno reaccionario", haciéndose eco de dirigirse en dirección a La Moneda para pedir la destitución del presidente Alessandri (Ortiz: 251-254). En su discurso, evocaría el ejemplo de la Revolución Cubana, declarando que "Nosotros los chilenos debemos responder a este llamado y ser capaces de tener nuestra Sierra Maestra. Debemos desde este instante luchar con nuestras armas, con nuestros puños, con nuestro esfuerzo y valentía. Cuando el pueblo se lanza a la calle nadie lo detiene" (Vitale 1961: 10).

La histórica jornada combativa deja un saldo represivo para los trabajadores de 35 heridos y 2 muertos. En los días siguientes, Clotario Blest será tomado detenido por su presunta responsabilidad en las revueltas. Sin embargo, no serán sólo las fuerzas del orden las que pongan freno a las protestas populares. Los partidos hegemónicos dentro de la CUT, particularmente el Partido Comunista (PC), no tolera la actitud revolucionaria de Blest (Vitale 1998: 363). Su nueva impronta "subversiva", sobrepuesta a su 
conciliador accionar en las filas del movimiento sindical, le trajo como consecuencia ser blanco de permanente hostigamiento por parte de los comunistas chilenos, lo que se extrapoló a un áspero ambiente al interior de la más grande plataforma obrera del país.

Al recobrar su libertad, Luis Vitale cuenta que Clotario emplazó a los sectores revolucionarios del sindicalismo chileno, con el objetivo de formar una estructura clandestina al interior de la clase trabajadora (Vitale 1998: 365). Se llamó "Movimiento 3 de Noviembre" (M3N), en homenaje a las jornadas de protestas de aquel día. Si bien esta organización tuvo como fin meramente la articulación sindical para hacer frente a las agresiones del hegemónico sector reformista dentro de la CUT (Álvarez 2014: 50), se convirtió en el primer germen de reagrupamiento revolucionario tras el triunfo de la Revolución Cubana en Chile. Asimismo, constituye un nuevo punto de quiebre en la trayectoria de Blest, ahora desde la dimensión militante. Aunque el M3N no fuera un partido, dejaba atrás su accionar apartidista, pues esta agrupación se desenvolvería bajo las mismas lógicas conspirativas del quehacer político-orgánico.

Este proceso de reagrupamiento de sindicalistas revolucionarios se nos presenta como un naciente antecedente en la configuración de lo que será la NIRCH. Variadas matrices ideológicas se fundieron en su interior, cohabitando el disgregado trotskismo ${ }^{2}$, el anarcosindicalismo liderado por Ernesto Miranda ${ }^{3}$, socialistas revolucionarios, comunistas disidentes ${ }^{4}$, etcétera. Clotario Blest tomó las riendas de este proceso unitario.

Para hacer la revolución en Chile, Clotario Blest y sus compañeros, consideraron que no era suficiente mantener una mera coordinación sindical dentro de la CUT. Si bien no estaban las condiciones para crear un nuevo partido revolucionario, la superación del M3N por una nueva plataforma de carácter multisectorial, imperaba como tarea por aquel entonces. El 25 de septiembre de 1961, Blest, junto al dirigente anarcosindicalista Ernesto Miranda, hicieron circula una "Carta-Invitación a la asamblea de

\footnotetext{
${ }^{2}$ Es importante destacar la participación de Luis Vitale y Humberto Valenzuela, que desde una de las referencias del POR chileno, fueron una de las fuerzas más activas en el proceso de unidad. Esta organización, en 1960, declaró en una resolución congresal que la acción sindical y la acción en los Comités de Defensa la Revolución Cubana, eran las tareas principales del periodo. ("Resoluciones del primer congreso latinoamericano del trotskismo: por el camino de la revolución mundial y latinoamericana" (1960). Específicamente, el apartado: "Chile: la situación general. Perspectivas y tareas)".

${ }^{3}$ Destaca la participación de Ernesto Miranda, líder del Movimiento Liberatorio 7 de julio. Tal fue el poder que ejerció la Revolución Cubana en este sector, que el mismo Miranda habría viajado a conocer Cuba en el año de 1959. (Del Solar, Felipe y Andrés Pérez. 2018: 58).

${ }^{4}$ Ver siguiente acápite concentrado en la figura de Enrique Sepúlveda y "Vanguardia".
} 
fuerzas revolucionarias a realizarse el 22 de octubre a las 9 horas. en el Teatro Princesa". La misiva convocaba a superar "la mentalidad legalista y electorera, burocrática, rutinaria y economista", estipulando que la "acción del nuevo movimiento será eminentemente revolucionaria en todos los órdenes de la vida sindical y política del país". El folleto, en su contraportada, termina diciendo: "Unidos indestructiblemente a los intereses de los trabajadores de Chile, el movimiento defenderá las proyecciones históricas de la Revolución Cubana para la emancipación de los pueblos de América Latina frente a todo ataque imperialista [...]." (Septiembre de 1961).

De aquella cita, surgió el Movimiento de Fuerza Revolucionario (MFR), donde cada una de las estructuras federadas mantenía su independencia política de la macroestructura, aunque, en el trabajo multisectorial desplegaron sus esfuerzos mancomunados (Álvarez 2014: 54). La renuncia de Clotario Blest a la presidencia de la CUT $^{5}$ no trajo consigo un abandono por la disputa de la hegemonía de ese espacio de lucha. ${ }^{6}$ Se crearon los "Consejos Revolucionarios Estudiantiles", agrupando a los jóvenes secundarios y universitarios bajo una misma plataforma (Movimiento de Fuerzas Revolucionarias, 1962). Una de las principales tareas del nuevo movimiento fue la activa solidaridad con Cuba. Luis Vitale, escribe en su sexto tomo de "Interpretación Marxista de la Historia de Chile": "El MFR se convirtió en motor de los Comité de Defensa de la Revolución Cubana y se opuso decididamente a la resolución de Alessandri de romper relaciones diplomáticas con la Cuba socialista" (Vitale 1998: 366).

Con un: "En representación del MFR de nuestra patria", partirá la carta que le escribió Clotario Blest a Fidel Castro con fecha 25 de enero de 1962. Blest, en nombre del reagrupamiento revolucionario, declara su irrestricto apoyo a la Revolución Cubana. A su vez, le deja ver a Castro la principal dificultad de emprender la lucha revolucionaria en Chile: "Los amortiguadores de un artificial y engañoso régimen político de representación popular, hacen extraordinariamente difícil nuestra acción, pero ello no arredra a nuestro pueblo que sabrá cumplir su misión histórica, así como lo hicieran los heroicos luchadores de la Sierra Maestra hasta alcanzar el triunfo final y definitivo" (Salinas 1980: 263-264).

\footnotetext{
${ }^{5}$ Clotario Blest renunció a la presidencia de la CUT el 28 de agosto de 1961.

${ }^{6}$ En el $3^{\circ}$ Congreso Nacional de la CUT, a efectuarse los días 1 a 5 de agosto, el MFR participó con un $13 \%$ de los delegados. Desde esa elección, nunca más contó con un miembro en el directorio.
} 
A través del liderazgo de Clotario Blest, la NIRCH inició un proceso de reagrupamiento entorno a las ideas de la revolución y camino insurrecto, sin embargo, esta radicalidad quedó en el plano discursivo, pues "los amortiguadores" que le hacía referencia a Fidel Castro siguieron primando en la praxis de los grupos convergentes. En la antesala de la elección presidencial de 1964, Blest cuenta que Salvador Allende convocó a la directiva del MFR para solicitarle su apoyo en el proceso eleccionario. Allende, con su habilidad política, habría comprometido incorporar elementos programáticos revolucionarios en su campaña. Blest, Miranda, Sepúlveda, Valenzuela y Vitale, aceptaron apoyar una vez más la cuestión electorera (Echeverría 2013).

\section{Enrique Sepúlveda: por la razón y la fuerza}

A diferencia de Clotario Blest, Enrique Sepúlveda siempre fue un hombre “partidario”, mimetizándose su trayectoria política con los orígenes y desarrollo del trotskismo chileno. En la década de 1920, mientras cursaba sus estudios de medicina en la Universidad de Chile, se afilió a la Federación Juvenil Comunista (FJC). Fue expulsado del PC en 1933 por trotskista (Partido Comunista 1933). Ese mismo año se adhirió a la Izquierda Comunista (IC), sección precursora de la IV internacional en Chile. En 1936, constituyó el Grupo Bolchevique Leninista, sector minoritario dentro de la IC, que resistió el ingreso en masa al PS. En 1937, se fundó el Partido Obrero Revolucionario (POR), convirtiéndose en su Secretario General (Valenzuela 2008: 124-125), cargo que ostentará hasta la división de esta organización a fines de la década de 1940 (Álvarez 2014: 37). Aunque en la década del 50 su trayectoria política se vuelve difusa: una versión nos dice que luego del quiebre se habría replegado de la contingente política, apoyando meramente la formación de dirigentes sindicales (Enrique Sepúlveda Marshall, entrevista personal, 23 de septiembre de 2014); y otra. más consistente con su propia biografía, lo vincula a los sectores de izquierda que apoyaron el segundo gobierno de Carlos Ibáñez del Campo (Valdés 2006), quien encarnaba un cierto ideario "nacional populista"7.

El Dr. Enrique Sepúlveda, reapareció públicamente como flamante Secretario General de la Vanguardia Nacional Marxista (VNM), la que surgió en diciembre de 1960. La "Vanguardia", fue el primer partido político de la izquierda radical chilena emergido por los efectos de la Revolución Cubana, agrupando entre

\footnotetext{
${ }^{7}$ Bania Bambirra dice que el peso del "nacional populismo" en América Latina amortiguó la construcción de una nueva izquierda. En esa misma dirección, es importante destacar la figura de Oscar Waiss, una de las principales figuras del reagrupamiento revolucionario luego de su expulsión del PS en 1961. Waiss, habría sido uno de los tantos elementos de la izquierda que fue parte del gobierno de Carlos Ibáñez del Campo.
} 
sus filas a disidentes de los partidos comunista y socialista, más novatos militantes, que se sentían atraídos por el reciente triunfo de los barbudos caribeños. Desde su manifiesto constituyente, llamado "Por la razón y la fuerza", los "vanguardistas" dejaron entrever que los vientos insurreccionales provenientes desde el Caribe redibujaban el nuevo sendero que conduciría a la Revolución Chilena, exigiéndose para aquello el reagrupamiento de los auténticos comunistas y, vigorizando de paso, aquella vieja idea de la conquista del poder a través de los métodos revolucionarios (Diciembre de 1960).

Si bien la Revolución Cubana inspiró la constitución de la "Vanguardia", las coordenadas internacionalistas de su sector fundador y mayoritario seguían oscilando dentro de la órbita socialista hegemónica, no ocultándose su simpatía por las dos grandes revoluciones rojas: Soviética y China. Esta inclinación al comunismo moscovita, especificamente al elegado de Stalin, que además legitimaba en alguna medida la Revolución China de Mao Tse Tung, respondió a que el grueso de sus militantes provenían de uno de los desprendimientos más emblemáticos de la historia del PC, constituyendose un grupo que luego se llamará "Movimiento Revolucionario Antiimperialista” (MRA).

EL MRA operó en el trayecto de la década de los cincuenta, con cuadros de base al interior de la cantera comunista, más un sector que ya había sido expulsado. Este grupo era liderada por Luis Reinoso, tercer hombre en importancia en la dirigencia comunista hasta 1951 (Loyola 2008), quien fuera acusado de “violencia y terrorismo" (Lafertte 1971: 351-352). Los reinosistas, en tiempos de la "Ley Maldita", se abocaron al trabajo de inteligencia, con el objetivo de poder sortear la envestida represiva. Además, utilizaron las herramientas de "acción directa" y "autodefensa de masas", enmarcadas dentro de una estrategia defensiva, que tenía como corlario final la mera recuperación de las garantías democráticas (Álvarez 2015: 103); no siendo homologable su accionar a las leyes de la "violencia revolucionaria" que acentará posteriormente la Revolución Cubana: la conquista del poder político por la vía insurreccional.

Ernesto Benado, miembro del MRA, declaró que el nombre de la organización fue ocurrencia del mismo Luis Reinoso, quien utilizó la nomenclatura "antiimperialista" para frenar las acusaciones que lo difamaban desde su ex organización de ser un agente del imperialismo (Ernesto Benado, entrevista personal, 5 de junio de 2014). Pocas veces se observó tanta beligerencia del PC contra una de sus disedencias políticas y, tal animadversión, tuvo su resonancia en la apertura de relaciones de la "Vanguardia" con las autoridades de la Revolución Cubana. 
El primer intento de la VRM por estrechar vínculos con los cubanos fue a través del viaje que realizó Ernesto Benado y Jorin Pilowsky a La Habana en 1962. Estos ex destacados cuadros del MRA, en su afiliación social al "Instituto Popular de Profesionales y Técnicos", aprovecharon la oportunidad de sumarse a la delegación de esa institución que viajó a Cuba. Siempre bajo la mirada atenta de los comunistas chilenos, que hegemonizaban la delegación, tuvieron la posibilidad de participar activamente de la agenda que incluyó entrevistas con las principales autoridades de la Revolución Cubana. Benado recuerda:

Tanto Jorin como yo mismo fuimos entrevistados varias veces por personeros que se identificaban como integrantes del G2 [inteligencia cubana]. Era tal la presencia del PC chileno, que parte de las entrevistas revelaban la desconfianza de algunos sectores cubanos hacia nosotros. Pero en general, las conversaciones terminaban con una manifestación de interés hacia VRM y la promesa que la Revolución Cubana, que tenía brazos muy largos, tomaría contacto con nosotros en Chile. (Ernesto Benado, entrevista electrónica, 28 de febrero de 2018).

¿Se cumplió la promesa de los cubanos? Según Ernesto Benado, sí. Esto habría sucesido através de Pedro Martínez Pírez, miembro del servicio diplomático cubano, quien se estableció en Chile entre 1962 y 1964. Relativizamos la intensidad del "contacto" con la VMN que declara Benado, pues, Martínez Pírez se caracterizó en su estadía en el país por su estrecha vinculación con los comunistas chilenos, llegando a desempeñarse como periodista en su periódico oficial, "El Siglo” (EcuRed).

Benado y Pilowsky, a su regreso a Chile dictaron dos charlas inspiradas en su viaje a Cuba denominadas: “La lucha contra el sectarismo y la formación de un Partido Único Revolucionario” y “Trasendencia de la Revolución Cubana para América Latina” (Agosto de 1962). Se deduce de los nombres de estas ponencias los aprendizajes extraídos del proceso caribeño, apostando con ello al robustecimiento partidario a través de un proceso de unificación con otras organizaciones chilenas con vocación revolucionaria; reservandose esta tradición de corte stalinista sus principales intransigencias ideológicas ${ }^{8}$.

\footnotetext{
${ }^{8}$ Es importante destacar que el mismo Luis Reinoso, de nombre real Benedicto Rebeco Montecino, no estuvo dispuesto a cohabitar con otras expresiones ideológicas del marxismo, particularmente, con el la del trotskismo. Fundamentado en lo anterior, algunas versiones declaran que se marginó tempranamente de la construcción de la "Vanguardia", mientras que otras, sitúan su continuidad en una cierta calidad de mero asesor.
} 
Sin Reinoso, los reinosistas siguieron siendo mayoría dentro de la "Vanguardia", no obstante, desde su fundación la responsabilidad de Secretario General recayó en la figura del Dr. Enrique Sepúlveda. Probablemente el liderazgo de Sepúlveda, más la cruzada antisectaria en la que se encontraban sus camaradas "stalinistas", habrían configurado las posibilidades para que a mediados de 1962 la VNM se fucionara con el Partido Revolucionario Trotskista (PRT), que como bien lo enuncia su nomenclatura, se reconocía en la la tradición política fundada por León Trotsky. El primer número del periódcio "El Rebelde", como medio oficial de la formación, traía en su portada una foto de "Fidel Castro y guajiros en armas", anunciando además, un artículo sobre "Cuba y su revolución" (25 de julio de 1962). Sin duda, que las diferencias en materia de política internacional que mantenía estas disimeles dos almas eran aplacadas por la simpatía mutua que les generaba la Revolución Cubana (Álvarez 2014: 73).

Esta particular simbiosis stalinista/trotskista trajo consigo un pequeño cambio en el nombre de la vieja "Vanguardia", que pasó a llamarse Vanguardia Revolucionaria Marxista (VRM), por exigencia de los recien llegados, quienes sostenían que lo "nacional" distaba de su caracteristico espíritu político "internacionalista". Los nuevos "vanguardistas", provenían de la tradición trotskista que mayor inspiración encontró en los métodos insurreccionales de la Revolución Cubana. Uno de sus líderes, el ingeniero Reinaldo Muñoz, hablando en tercera persona a través de su nombre político "Zapata", cuenta: "En el PRT, organización a la cual se había integrado un ex dirigente de la juventud comunista (el compañero. Lautaro), se elabora una propuesta de estrategia revolucionaria, inspirada en la experiencia cubana" (Reinaldo Muñoz, entrevista electrónica con Pedro Valdés).

Si el PRT fue la organización trotskista que mayor influencia tuvo de la Revolución Cubana, Lautaro, de nombre Carlos Ramos, fue de sus dirigentes el que más se vinculó con el imaginario de lucha armada. El Dr. Ramos, fue el más voluntarista del grupo, siendo apresado en los meses y años siguientes por la colocación de artefactos explosivos. Este tipo de "acción directa" no fue la única dimensión que trabajaron los "vanguardistas trotskistas", sino que también comenzaron a realizar escuelas de guerrillas en la montaña, por tanto, adhirieron a la estrategia insurreccional de guerra de guerrillas convocada en sus inicios por la Revolución Cubana. Distanciándose de los métodos de sus compañeros "vanguardistas estalinistas", para operar con mayor holgura dentro de la VRM, crearon una estructura secreta denominada 
"Ejército Revolucionaria de Trabajadores y Estudiantes" (ERTE), lo que atrajo a jóvenes encantados con la idea de la revolución (Álvarez 2015: 106).

Independiente de las diferencias, el triunfo y desarrollo de la Revolución Cubana les exigió a los disidentes del reformismo chileno llevar adelante un proceso de reagrupamiento revolucionario, que superara el abismo del sectarismo. Uno de sus textos de 1963, declara:

Es indudable que a partir de la revolución cubana, del carácter socialista en el que devino la lucha del pueblo cubano, de la denuncia del sectarismo por el camarada Fidel Castro y de la proclamación hace un año, de la Segunda Declaración de La Habana, que todo un nuevo periodo de reorganización y de orientación vitalizadora, recorre a América Latina. Lenta pero firmemente frente a las organizaciones tradicionales de la clase obrera, que vivían en el marasmo del reformismo y el revisionismo, se han ido creando nuevas organizaciones dinámicas y revolucionarias, que poco a poco van jugando su rol de dirección en las luchas de masas de América. (1 de mayo de 1963)

Reivindicando el ejemplo de la Revolución Cubana, la VRM dirigió sus objetivos de reorganización desde una doble dimensión. Una, resquebrajar las bases militantes de los partidos reformistas de masas. Desde las filas del PC, vinculó a un reducido grupo de jóvenes descolgados que se nucleaban en una organización llamada Movimiento Revolucionario Comunista (MRC), los que eran liderados por Gabriel Smirnow (Gabriel Smirnow, entrevista personal, 19 de mayo de 2014). Su estrategia rupturista tuvo mejor suerte en las juventudes del PS, logrando atraer a más de un centenar de cuadros de Santiago y Concepción ${ }^{9}$. La otra arista, era seguir sumando desde los márgenes de la izquierda radical, donde afiliaron a algunas individualidades (René Parra, entrevista personal, 14 de junio de 2014) y colectivos trotskistas disgregados, como el Grupo Revolucionario Marxista (GRM) de Concepción.

El Dr. Enrique Sepúlveda, en representación de la VRM, a mediados de 1963 fue invitado al décimo aniversario del asalto al Cuartel Moncada, "a las festividades del 26 de julio, gracias a la generosa invitación del gobierno Revolucionario Cubano" (Septiembre de 1963). Sobre su viaje a La Habana, el Secretario General de la "Vanguardia" se limitó a enumerar en el órgano de difusión oficial de su Partido las conquistas más sobresalientes de la revolución, no precisando en sus anotaciones el desarrollo de otras

\footnotetext{
${ }^{9}$ Ver acápite siguiente.
} 
actividades de carácter político formal, posiblemente, porque no existieron ${ }^{10}$. El hijo de Sepúlveda, del mismo nombre y profesión, recordará en entrevista con este autor la frustración de su padre al no poder establecer relaciones políticas de mayor solidez con la administración de Cuba (Enrique Sepúlveda Marshall, entrevista personal, 23 de septiembre de 2014). Ernesto Benado, a su vez, recordará que en la isla tuvo mayor contacto con la delegación China que con los dirigentes de la revolución caribeña (Ernesto Benado, entrevista electrónica, 28 de febrero de 2018).

Con la misma intensidad que influenció su constitución, la cuestión internacional gravitó en el resquebrajamiento de la "Vanguardia". Los primeros días de mayo de 1964, la VRM se dividió en dos: un grupo encabezado por los excomunistas, quienes respaldaron sus posicionamientos políticos en las ideas de la Revolución China; y, otro sector, encabezado por Enrique Sepúlveda, quienes se referenciaron en las ideas de la Revolución Cubana. Sepúlveda, más los trotskistas y la mayoría de la juventud del partido, pasaron a denominarse "VRM-El Rebelde", al mantener en su poder el periódico de la organización. Más que afectarle numéricamente la división, a este fragmento vanguardista la ruptura le otorgó mayor coherencia ideológica, pudiendo resolver una de las principales diferencias estratégicas que mantenía con los pro-chinos: el carácter de la revolución. Desamarrados de la idea maoísta de la "Revolución Democrática Popular", alzaron de inmediato las banderas de la "Revolución Socialista" (Álvarez 2014: 77).

Los pro-chinos chilenos, como hemos contemplado, los primeros años fueron seguidores de la Revolución Cubana, pero tiempo después asumirán la misma posición crítica contra Cuba que su centro ideológico internacional. A pie de página, Bambirra en su libro "Diez años de insurrección en América Latina", identificó en su clasificación de la "izquierda revolucionaria" a la "Vanguardia" como una de las organizaciones perteneciente a la "nueva izquierda" (Bambirra: 58); sin embargo, quien será continuadora de esta tradición será la VRM-El Rebelde.

La VRM-El Rebelde, fue el sector que mantuvo su ligazón al MFR. Asimismo, dentro del espacio mancomunado fue la organización que utilizó con mayor intensidad el imaginario insurrecto de la Revolución Cubana como eje central de su orientación política. Una forma de medir esto, se desprende de que casi la totalidad de los ejemplares del periódico "El Rebelde" publicara en disímil medida sobre el

\footnotetext{
${ }^{10}$ En la prensa oficialista cubana no existen registros de la estadía del Dr. Enrique Sepúlveda en Cuba.
} 
proceso revolucionario en Cuba: notas periodísticas, análisis políticos y palabras de homenaje. En las páginas de su órgano de difusión oficial (incluso antes del quiebre), la "Vanguardia" decía representar fielmente en Chile los postulados de la Revolución encabezada por Fidel Castro. Esto atrajo la simpatía de aquella nueva generación de militantes formados al calor de los acontecimientos provenientes del rojo Caribe, quienes, en la búsqueda de una alternativa política con vocación insurreccional, encontraron entre sus filas un fértil espacio para la construcción de una referencia revolucionaria.

\section{Miguel Enríquez: una nueva generación de revolucionarios chilenos}

Miguel Humberto Enríquez Espinosa, reconocido por haber liderado el Movimiento de Izquierda Revolucionaria (MIR), nació el 27 de marzo de 1944 en el Puerto de Talcahuano, a 13 kilómetros de la ciudad de Concepción. De "pequeña burguesía intelectual” (Álvarez 2019), identificó su proceder familiar, pues su padre fue el reconocido médico y académico Humberto Enríquez Frödden, quien a fines de la década de 1960 se convirtió en el rector de la Universidad de Concepción, para luego asumir como ministro de educación del Gobierno de la Unidad Popular (Enríquez, 1994). Asimismo, fue sobrino de dos destacadas figuras políticas de la época: Inés Enríquez Frödden, la primera mujer intendenta y diputada de la historia de Chile.

Siendo espectador de las protestas populares de abril de 1957, la efervescencia de la campaña electoral de Salvador Allende en 1958 y el triunfo de la Revolución Cubana en 1959 (Álvarez 2019), el despertar político Miguel Enríquez se caracterizó en esta primera etapa esencialmente por la (auto)formación política, la que ejercía con un grupo de compañeros del "Liceo de Hombres”. Será recién en 1961, al ingresar a la Universidad de Concepción, donde asumirá el camino del activismo político.

Para Miguel Enríquez y sus compañeros de generación el punto de ebullición con la Revolución Cubana no fue su triunfo propiamente tal, ni sus dos primeros años marcados aún por las indefiniciones en el campo ideológico, sino se produjo con los acontecimientos de abril de 1961 al vencer el Ejército Rebelde la invasión promovida por el imperialismo norteamericano en Bahía Cochino y, con ello, la declaración del carácter socialista de la revolución proclamada por Fidel Castro (1961). "Esa no era una frase oratoria, sino una definición”, escribió Fernando Martínez Heredia, para referirse al tipo de socialismo que surgía en Cuba, el cual se sostenía bajo la consigna del "vencer o morir" (2017:34). 
Aclaradas las coordenadas político-ideológicas de la Revolución Cubana, la del socialismo revolucionario, Miguel Enríquez da sus primeros pasos militantes. Beatriz Allende, hija de Salvador Allende, cursando por aquel entonces un año superior en la carrera de medicina en la Universidad de Concepción, evoca en sus recuerdos aquellas jornadas de protesta y solidaridad contra la invasión a Cuba:

Tuve compañeros muy lúcidos, muy intrépidos. Miguel Enríquez entre ellos. Todavía no era Secretario General del Movimiento de Izquierda Revolucionaria, el MIR. Todavía no había nacido el MIR cuando lo conocí. Pero afloraban sus condiciones de líder. Estudiaba medicina como yo. Afianzamos una amistad definitiva. El triunfo de la Revolución Cubana nos identificó de idéntica manera. A partir de esta hazaña, determinante en el devenir de América Latina, vivíamos enardecidos día a día. Cuando intentaron invadir a Cuba por Playa Girón, los estudiantes de la Universidad de Concepción asaltamos el consulado yanqui y prendimos fuego a la bandera de Estados Unidos. Miguel marchaba en la primera línea. Y con los estudiantes, hermanados, los mineros del carbón se congregaron elevando el clamor de condena al imperialismo agresor, paralizando minas y abriendo la convocatoria para acudir en calidad de combatientes internacionalistas a pelear en defensa de Cuba contra el enemigo común. (Febrero de 1977).

“¡Cuba Libre!”», partió escribiendo Miguel Enríquez en su diario de vida esa misma noche de abril de 1961 que rememoró Tati Allende, agregando:

El mundo se agita, los pueblos del mundo entero claman por el cese de la intervención yanqui en Cuba. Chile, sus estudiantes y obreros ya salieron a la calle. Hoy y ayer apedreamos el consulado. Hoy robamos la bandera del consulado. Hoy fui apaleado por primera vez. Siento el odio al órgano represor de la burguesía el "Cuerpo de Carabineros”. (Álvarez, 2019).

Miguel Enríquez terminó de escribir esa noche: "Viva Cuba, Viva la Revolución Socialista”. Enríquez recién había cumplido los 17 y Beatriz Allende (Álvarez, 2017) sólo tenía 18. Con este "bautizo político" $" 11$ al calor de las jornadas de movilización y solidaridad con el pueblo caribeño una nueva generación de militantes se sumaba a la acción política apelando al ejemplo de la Revolución Cubana.

\footnotetext{
${ }^{11}$ Fernando Martínez Heredia, en entrevista con el autor, febrero de 2017, recuerda en sus conversaciones con Miguel Enríquez, que este le habría contado sobre aquellas jornadas de solidaridad con el pueblo cubano, declarándole que este habría sido su "bautizo político".
} 
Miguel Enríquez dejaba su primera etapa del "despertar político”, donde según sus propias palabras: "En mis años de Liceo me dedico a leer marxismo [...]. No desempeño labor práctica. Soñamos” (Álvarez 2019). Junto a sus amigos más cercanos de la era escolar: Bautista van Schouwen ${ }^{12}$, Claudio Sepúlveda (Claudio Sepúlveda, entrevista personal, 26 de marzo de 2016) y Marcelo Ferrada (Marcello Ferrada, entrevista telefónica, abril de 2016), decidieron ingresar a militar en una organización política que diera cuenta de sus inquietudes revolucionarias ¿Dónde? En Concepción tres estructuras de izquierda los podrían albergar. Enríquez, desechó de plano al PC, por ser acérrimo defensor de la "vía pacífica”. Dirá: "No puedo entrar a un Partido que ya no es revolucionario". El POR, que para su opinión tenía "la mejor posición ideológica", fue descartado por su débil influencia en las masas. Consiente de sus contradicciones internas, terminará por incorporarse al PS, considerando que podrán: “allí aprovechar toda la estructura de ese partido, su base, su organización; etc. Madurarlas y prepararla, para el momento decisivo, el día de la gran revolución. Para que en ese entonces no sucumbe a su caduca y corrompida burocracia, que los tratará de vender." (Álvarez 2019).

Su militancia se desarrollará en las Juventudes Socialistas de la Universidad de Concepción, espacio que era liderado por el estudiante de leyes Ariel Ulloa (Ariel Ulloa, entrevista telefónica, 27 de febrero de 2017). En la Escuela de Medicina crearon la base "Sierra Maestra", nombrada así, en homenaje a las montañas donde Fidel Castro y los suyos desplegaron la lucha armada contra la tiranía de Fulgencio Batista. Crearon la Revista Revolución, espacio teórico de agitación “insurreccional”. En el trayecto del año de 1962, solidarizaron activamente con las luchas de los mineros de Lota y Coronel. Fueron miembros activos de la solidaridad con Cuba, participando Marcelo Ferrada en el Instituto Chileno-Cubano de la Cultura (Marcelo Ferrada, entrevista telefónica, abril de 2017).

Desde el punto de vista ideológico, los acontecimientos de Playa Girón tuvieron importantes repercusiones en Miguel Enríquez y sus compañeros: una vez declarado por Fidel Castro el carácter socialista de la revolución, esta nueva generación de militantes imbricará esta categoría política en su acervo teórico. Lo importante de destacar, es que este ensamblaje doctrinal, tiene simultaneidad con los orígenes de su militancia. Esto quiere decir que, desde el inicio de su praxis revolucionaria, no estuvieron sometidos a la estrategia hegemónica de las décadas anteriores: “el socialismo por etapas".

\footnotetext{
${ }^{12}$ Asesinado y desaparecido por la dictadura militar en diciembre de 1973.
} 
En el campo de las ideas revolucionarias, 1963 fue esencial para la comprensión de la nueva izquierda latinoamericana. Ese año comenzarán a circular por Latinoamérica dos libros estratégicos: la traducción al castellano del Fondo de la Cultura Económica de la obra más célebre de Frantz Fanon, "Los condenados de la tierra", donde estableció que la violencia revolucionaria era la única forma poder liberar a los pueblos oprimidos. Asimismo, en septiembre de ese año, se publicará el texto de Ernesto Guevara, "Guerra de Guerrillas. Un método", el que afirmará que "no siempre hay que esperar a que se den todas las condiciones para la revolución; el foco insurreccional puede crearlas". Con los manuscritos de Fanon y Guevara, la idea del "foco" o "foquismo" se robustecerá teóricamente.

Volviendo a Concepción: "Desde septiembre de 1963 existimos como [Movimiento Socialista Revolucionario] (MSR)" (Álvarez 2019), escribe Miguel Enríquez en sus diarios de vida, para referirse al trabajo fraccional que comenzaron a realizar al interior de la Juventud Socialista. La autodenominación "socialista revolucionario", tenía para los jóvenes como objetivo cumplir un rol diferenciador para con las tendencias conservadoras al interior del PS, que insistían en no cuestionar la política de "vía pacífica al socialismo". A fines de ese mismo año, Marcelo Ferrada será el primer miembro del grupo original que viajará a Cuba. Edgardo Enríquez, hermano de Miguel y alumno de ingeniería de la Universidad de Chile, será el encargado de constituir el MSR entre los estudiantes socialistas de Santiago.

Paralelamente, Miguel Enríquez, en otro pasaje de su Diario de Vida aludiendo a 1963, anotó: "conocimos a Lautaro de la VRM" (Álvarez 2019). La línea estratégica insurreccional del sector de la "Vanguardia" que, estructuró el ERTE, inspirada en la Revolución Cubana, comenzó a seducir a este grupo de jóvenes. Hasta que lograron incorporarlos a las filas de la VRM" (Vitale 1999: 7). Por tanto, Enríquez y sus compañeros, con ello ingresaron al proceso de confluencia que desarrollaba la NIRCH.

En febrero de 1964, luego del XX Congreso Nacional de los socialistas chilenos, los jóvenes publicaron un folleto dando a conocer las razones de su alejamiento del PS, más su adherencia al proyecto político de la VRM. El documento se denominó "Insurrección Socialista", y termina diciendo:

"Enteramente responsable de nuestros destinos como revolucionarios fieles a la bandera que hemos defendido en el Partido Socialista en nombre de 140 militantes nos hacemos un deber LLAMAR A NUESTROS CAMARADAS Y AMIGOS, a los trabajadores que han alentado dentro y fuera del Partido Socialista nuestra conducta política, a INCORPORARSE 
A LA VANGUARDIA REVOLUCIONARIA MARXISTA, que se ha transformado en el núcleo aglutinante del futuro y gran partido marxistaleninista de masas que conducirá a los trabajadores a la revolución, el poder político y al socialismo para levantar otra estrella solitaria que diga ipresente! a la gran bandera estrellada que ondea orgullosamente en manos de Fidel Castro en Cuba (1964).

El ejemplo de la vía revolucionaria de Cuba era preponderante. Sin embargo, en el documento "Insurrección Socialista" también declararon su apoyo a la candidatura presidencial de Salvador Allende ¿Apoyaban las dos vías: la pacífica y la insurreccional? Al igual que los cuadros de la vieja izquierda revolucionaria que impulsaban la $\mathrm{NIRCH}$, los jóvenes rupturistas no tenían del todo solucionado el problema de acceso del poder. Consideraban que ambas se podían unir en un proceso revolucionario. Quizás, solo fueron arrastrados por la coyuntura política y correlación de fuerzas al interior de las izquierdas, la que no mostraba otra alternativa.

Al mes que el grupo de Miguel Enríquez se incorporó a la Vanguardia, esta realizó su primer Congreso Nacional y, como contemplamos en el acápite anterior, se quebró en dos bloques. Como todas las rupturas, sus razones radicaron en una mezcolanza de componentes ideológicos, como de discrepancia en materia de afinidades personales. No obstante, la cuestión internacional tuvo un alto nivel de implicancia en la fisura. El mismo Enríquez avalará esta idea en sus anotaciones: "El MSR ingresó a la VRM, y aquí crecimos. Después en marzo esta se dividió entre estalinistas y otro sector de izquierda, que se guiaba no por China, sino por Cuba. Nos fuimos.” (Álvarez 2019).

Una de las últimas resoluciones Jorge Alessandri antes de terminar su mandato de presidente, fue cesar las relaciones diplomáticas con Cuba. La izquierda en su amplitud salió a cuestionar la decisión tomada por el gobierno. Ante los ojos de Miguel Enríquez y sus compañeros, este apoyo tuvo menguada intensidad en la dirigencia política de la izquierda chilena. Derechamente, consideraron que la actitud de Salvador Allende, el FRAP y la CUT, no fue lo suficientemente enérgica para defender a la Revolución Cubana. Para ellos, lo correcto habría sido convocar a una movilización permanente: "Huelga General”, pues, lo que estaba en juego no eran solo las vinculaciones consulares entre los dos países, sino que la subyugación a las ordenanzas del intervencionismo imperialista. Tomando como ejemplo Brasil ${ }^{13}$, los jóvenes creyeron

\footnotetext{
${ }^{13}$ El Golpe de Estado de Brasil de marzo de 1964 que depuso como presidente a Joao Goulart, fue el inicio de la política golpista en América Latina impulsada desde el gobierno norteamericano.
} 
que esta se expresaría para Chile en forma de Golpe de Estado, en el caso de salir electo Allende como presidente en los días siguientes.

En palabras del mismo Enríquez, esta fueron las acciones que realizaron en Concepción con sus compañeros más cercanos al enterarse de la noticia del cese de las relaciones diplomáticas con la Revolución Cubana:

Los acontecimientos se han sucedido en forma acelerada. El 14 - VIII - 64 el gobierno rompió relaciones con Cuba. Nuestra reacción fue inmediata, aunque fuimos sorprendidos en la misma noche. Viriato ${ }^{14}$ redactó un panfleto, Atacama ${ }^{15}$ lo escribía a máquina y fue sacado en el mimeógrafo del "Cabezón"16. No en forma muy cauta. 3.000 ejemplares. Se repartió en la noche misma en el Hogar [Universitario]. Al día siguiente en toda la Universidad. Esa noche se hizo rayado mural nocturno clandestino. En la asamblea de Federación al día siguiente se pidió paro general indefinido. Tuvimos que fundirlo con el del FRAP. Son 24 horas. Tratamos de hacer desfile, fue imposible. Al día siguiente en cesión de centro volvimos a hablar. Bauchi, aclaró que a la contrarrevolución, opondremos la revolución. (Álvarez, 2019).

Si bien las palabras de Miguel Enríquez demuestran un total compromiso con lo que consideraban una agresión de los tentáculos imperialista a la Revolución Cubana, estas acciones de solidaridad se enmarcan en el escaso margen de incidencia política que tenían con su grupo, reducido principalmente al campo universitario.

Ya sabemos que Allende holgadamente fue derrotado en las elecciones presidenciales de septiembre de 1964. Miguel Enríquez, junto a Bautista van Shouwen, escribieron un artículo, denominado "Los fariseos gobernantes y los generales y reclutas de la derrota", apuntando al reformismo como responsables de la estrepitosa capitulación. Para los jóvenes estudiantes de medicina de Concepción, el triunfo de los democratacristianos en las urnas correspondió sobre todo a la actitud vacilante de las direcciones de los partidos reformistas, a quienes llamaban los generales del FRAP. Asimismo, los acusaron abiertamente de haber abandonado la solidaridad con Cuba en virtud de la captación de sufragios. (Álvarez 2018).

\footnotetext{
${ }^{14}$ Nombre político de Miguel Enríquez.

${ }^{15}$ Nombre político de Marcello Ferrada.

${ }^{16}$ Apodo de Sergio Sepúlveda.
} 
A sazón de la derrota, esta nueva generación de militantes no pudo estar más de acuerdo con la política de la "bancarrota electoral" impulsado por los sectores de la NIRCH. Se abría la oportunidad de eclipsar definitivamente con la característica sobresaliente de la nueva izquierda revolucionaria latinoamericana: la conquista del poder por la vía insurreccional ${ }^{17}$. Se confirmó, lo que ellos siempre postularon, la revolución había que hacerla a lo cubano.

\section{Conclusión}

La influencia de la Revolución Cubana permitió un camino de reagrupamiento revolucionario inédito en la historia de Chile, amparando sin sectarismos diversas matrices político-ideológicas en su interior. Además, diversas generaciones militantes participaron de este proceso.

Si bien la NIRCH (1959-1964) arraigó la estrategia de revolución socialista a través de la vía insurreccional emanada desde la Revolución Cubana, esta, no terminó siendo más que un discurso, pues finalmente su política se encontró sujeta a los vaivenes de la cuestión electoral, es decir, a las directrices de la izquierda reformista. Por tanto, tuvo un desarrollo disímil a las organizaciones del "primer momento" de la nueva izquierda latinoamericana.

La holgada derrota de Salvador Allende en las elecciones presidenciales de 1964 provocó que las fuerzas del reagrupamiento revolucionario dieron por caducada una la larga tradición electoral, acordando salir del campo de la discursividad, para concretar la construcción de un partido político militar de vanguardia que impulsara una estrategia insurreccional en Chile. Lo anterior, se expresará en que la mayoría de las agrupaciones participes de la NIRCH, exceptuando a los maoistas, fundaron el MIR en agosto de 1964. Con esto, también podemos concluir, que los procesos electorales fueron una condicionante medular para las decisiones estratégicas de la izquierda rupturista.

Los principales actores del reagrupamiento revolucionario en sus viajas a Cuba intentaron establecer vinculaciones con las autoridades de la Revolución, sin embargo, no se pudieron concretar relaciones formales, constituyéndose en este periodo una especie de "amor platónico" de la NIRCH con la

\footnotetext{
17 Miguel Enríquez comenzará a trabajar un documento que llevará es nombre: “La conquista del poder por la vía insurreccional", el que será presentado como tesis político militar en el congreso fundacional del MIR acaecido en los meses siguientes.
} 
Revolución Cubana, no existiendo una reciprocidad desde los hombres de Fidel Castro. La candidatura de Allende, el poderío de los partidos socialista y comunistas, la desconfianza al trotskismo, entre otros, serán elementos medulares para que los cubanos no "apadrinaran" a quien se declaraban los auténticos legatarios de la insurrección caribeña en Chile.

\section{Referencias bibliográficas}

Álvarez Vergara, Marco (2019), Mi felicidad es la lucha. Antología inédita del joven Miguel Enríquez. Santiago, Chile: Editorial Pehuén.

Chile: Editorial Pehuén. (2018), Bautista van Schouwen. Que la dignidad se haga costumbre. Santiago, (2017), Tati Allende. Una revolucionaria olvidada. Santiago: Editorial Pehuén. (2015), La constituyente revolucionaria. Historia de la fundación del MIR chileno. Santiago, Chile: LOM Ediciones.

Chile: Editorial Escaparate. (2014), La ruta rebelde. Historia de la izquierda revolucionaria. Concepción,

Bambirra, Vania (1972), Diez años de insurrección en América Latina. Santiago, Chile: Editorial Prensa Latinoamericana.

Barría, Jorge (1971), Historia de la CUT. Santiago, Chile: Ediciones Prensa Latinoamericana.

Castro, Fidel, "Discurso de Fidel Castro". CubaCu, [La Habana, Cuba]: 16 de abril de 1961. Web: http://www.cuba.cu/gobierno/discursos/1961/esp/f160461e.html

Del Solar, Felipe y Andrés Pérez (2018), Anarquistas. Presencia libertaria en Chile. Santiago, Chile: Ril Editores.

Echeverría, Mónica (2013), Anthistoria de un luchador. Clotario Blest 1823-1990. Santiago, Chile: LOM Ediciones.

Enríquez Frödden, Edgardo (1994), En el nombre de una vida. DF, México: Universidad Autónoma Metropolitana.

Fanon, Frantz, (2011), Los condenados de la tierra. La Habana, Cuba: Fondo Editorial Casa de las Américas.

Guevara, Ernesto. "Discurso al Primer Congreso Latinoamericano de Juventudes". 28 de julio de 1960. Web: 
https://www.archivochile.com/America_latina/Doc_paises_al/Cuba/Escritos_del_Che/escritosdelche002 2.PDF

Lafertte, Elías (1971), Vida de un comunista. 2 ed. Santiago, Chile: Editorial Austral.

Letts, Ricardo (1981), La izquierda peruana. Organizaciones y tendencias. Lima, Perú: Mosca Azul Editores.

Loyola, Manuel, 2008, “Los destructores del Partido': notas sobre el reinosismo en el Partido Comunista de Chile". Revista Izquierdas, $\mathrm{N}^{\circ} 2$.

Löwy, Michael (2007), El Marxismo en América Latina. Antología, desde 1909 hasta nuestros días (edición actualizada). Santiago, Chile: LOM Ediciones.

Martínez Heredia (2017), Fernando, Cuba en la encrucijada. La Habana, Cuba: Ruth Casa Editorial.

Orellana Valenzuela, Gilda (2012), Clotario Blest: sindicalista revolucionario y político de clase: por la emergencia del poder popular (siglo XX) (Tesis Magister Historia). Universidad de Chile, Santiago, Chile.

Ortiz, Óscar, (2008), Nuevas crónicas anarquistas de la subversión olvidada. 2 ed. Chile: Editorial La Simiente, 2008.

Palieraki, Eugenia (2014), ¡La revolución ya viene! El MIR chileno en los años sesenta. Santiago, Chile: Editorial LOM.

Pozzi, Pablo y Claudio Pérez, ed. (2012), Historia oral e historia política. Izquierda y lucha armada en América Latina, 1960-1990. Santiago, Chile: LOM ediciones.

Regalado, Roberto (2012, La Izquierda latinoamericana en el gobierno ¿Alternativa o reciclaje?. DF, México: Editorial Ocean Sur.

Sader, Emir (2006) La venganza de la historia. Hegemonía y contrahegemonía en la construcción de un nuevo mundo posible. DF, México: Ediciones ERA.

Salinas, Maximiliano (1980), Clotario Blest. Santiago, Chile: Arzobispado de Santiago, Vicaría Pastoral Obrera.

Valenzuela, Humberto (2008), Historia del Movimiento Obrero Chileno. Santiago, Chile: Editorial Quimantú.

Valdés, Pedro (2006), Elementos teóricos en la formación y desarrollo del MIR durante el periodo 1965 -1970, (Tesis para optar al grado de Licenciado en Historia). Universidad de Valparaíso, Valparaíso, Chile.

Vitale, Luis (1961), Los discursos de Clotario Blest y la revolución chilena. Santiago, Chile: Editorial POR. 
(1998), Interpretación Marxista de la Historia de Chile. De Alessandri P. a Frei M. (19321964). Industrialización y modernidad. Tomo VI. Santiago, Chile: LOM Ediciones.

(1999). Contribución a la historia del MIR (1965-1970). Santiago, Chile: Instituto de Investigación de Movimientos Sociales Pedro Vuskovic. Web.

Partido Comunista de Chile (julio 1933). Hacia la formación de un verdadero partido de clase. Resoluciones de la Conferencia Nacional. Santiago, Chile

14 de marzo de 1959. A plaza llena "barbudos" recibieron vibrante homenaje de Chile a la Revolución Cubana. El Siglo.

26 de agosto de 1960. Se efectuó concentración que fue organizada por el comité de ayuda a Cuba, El Mercurio: 20.

1960. "Resoluciones del primer congreso latinoamericano del trotskismo: por el camino de la revolución mundial y latinoamericana". Santiago, Chile: Editorial Prensa Latinoamericana.

Diciembre 1960. Manifiesto de la Vanguardia Nacional Marxista Santiago, Chile: S/E.

Septiembre de 1961. Carta de invitación a la Asamblea de Fuerzas revolucionarias. Santiago, Chile: Sin Editorial.

25 de julio de 1962. Cuba y su revolución. El Rebelde, $\mathrm{N}^{\circ} 10$, Santiago de Chile.

Agosto de 1962. "Conferencia. Vanguardia Revolucionaria Marxista". Panfleto. Santiago, Chile. Consultado en el Instituto Internacional de Historia Social de Ámsterdam, fondo Marcelo Segal. 1

1962. Por la Unidad de los Estudiantes Revolucionarios. Manifiesto a los estudiantes chilenos. Santiago, Chile: Movimiento de Fuerzas Revolucionarias - Consejo Revolucionario Estudiantil.

1 de mayo de 1963. Un nuevo combate se ha iniciado contra el reformismo". El Rebelde $\mathrm{N}^{\circ} 14$, Santiago de Chile.

Septiembre de 1963. Vanguardia Revolucionaria Marxista invitada a Cuba. El Rebelde. N$^{\circ} 17$, Santiago de Chile.

1964. "Insurrección socialista”. Manifiesto.

Febrero de 1977. Entrevista a Beatriz Allende, Revista Mujeres, n², órgano de la Federación de Mujeres Cubanas. La Habana, Cuba.

"Pedro Martínez Pírez". EcuRed, [La Habana, Cuba], s/f: s/p. Web: https://ecured.cu/Pedro_Mart\%C3\%ADnez_P\%C3\%ADrez 